\title{
Benefits and harms of erythropoiesis-stimulating agents for anemia related to cancer: a meta-analysis
}

\author{
Marcello Tonelli MD SM, Brenda Hemmelgarn PhD MD, Tony Reiman MD SM, Braden Manns MD MSc, \\ M. Neil Reaume MD MSc, Anita Lloyd MSc, Natasha Wiebe MMath PStat, Scott Klarenbach MD MSc
}

Published at www.cmaj.ca on Apr. 30, 2009. An abridged version of this article appeared in the May 26, 2009, issue of $C M A J$ and is available at www.cmaj.ca/cgi/content/full/180/11/E62/DC2.

\section{ABSTRACT}

Background: Erythropoiesis-stimulating agents are used to treat anemia in patients with cancer. However, their safety and effectiveness is controversial. We did a systematic review of the clinical efficacy and harms of these agents in adults with anemia related to cancer or chemotherapy.

Methods: We conducted a systematic review of published and unpublished randomized controlled trials (RCTs) using accepted methods for literature searches, article selection, data extraction and quality assessment. We included RCTs involving anemic adults with cancer. We compared the use of erythropoiesis-stimulating agents with nonuse and assessed clinical outcomes (all-cause mortality, cardiovascular events and hypertension, health-related quality of life, blood transfusions and tumour response) and harms (serious adverse events) between groups.

Results: We identified 52 trials $(n=12006)$ that met our selection criteria. The pooled all-cause mortality during treatment was significantly higher in the group receiving erythropoiesis-stimulating therapy than in the control group (relative risk [RR] 1.15, 95\% confidence interval [CI] 1.03 to 1.29). Compared with no treatment, use of erythropoiesisstimulating agents led to clinically detectable improvements in disease-specific measures of quality of life. It also reduced the use of blood transfusions (RR $0.64,95 \% \mathrm{Cl} 0.56$ to 0.73 ). However, it led to an increased risk of thrombotic events (RR 1.69, 95\% Cl 1.27 to 2.24 ) and serious adverse events (RR $1.16,95 \% \mathrm{Cl} 1.08$ to 1.25 ).

Interpretation: Use of erythropoiesis-stimulating agents in patients with cancer-related anemia improved some disease-specific measures of quality of life and decreased the use of blood transfusions. However, it increased the risk of death and serious adverse events. Our findings suggest that such therapy not be used routinely as an alternative to blood transfusion in patients with anemia related to cancer.

Une version française de ce résumé est disponible à l'adresse www.cmaj.ca/cgi/content/full/180/11/E62/DC1

CMAJ 2009;180(11):E62-E71
$\mathrm{A}$ nemia related to cancer may be due to the cancer itself or it may be a complication of chemotherapy.

Because anemia is associated with adverse clinical outcomes in people with cancer, including impaired quality of life ${ }^{1}$ and decreased survival, ${ }^{2}$ treatment with erythropoiesis-stimulating agents has been widely used. These agents are costly, and reimbursement policies for their use in patients with cancer-related anemia vary across Canadian jurisdictions. Recent studies suggest that their use in such patients may be associated with an increased risk of adverse events such as thromboembolism. ${ }^{3}$ Potential adverse effects have also been identified in patients with chronic kidney disease. ${ }^{4,5}$

Therefore, an assessment of the efficacy and harms of erythropoiesis-stimulating agents in patients with cancer-related anemia would be useful to clinicians, and to jurisdictions that seek to develop an evidence-based reimbursement policy for these drugs. We conducted a systematic review based on work done for the Canadian Agency for Drugs and Technologies in Health ${ }^{6}$ to summarize the clinical efficacy and harms of these agents in adults with anemia related to cancer.

\section{Methods}

We conducted a systematic review of published and unpublished randomized controlled trials (RCTs) using accepted methods for literature searches, article selection, data extraction and quality assessment and reported our observations in accordance with existing guidelines. ${ }^{7.8}$ Full details are published elsewhere. ${ }^{6}$

\section{Literature search}

We searched MEDLINE (1950 to Oct. 22, 2007), EMBASE (1988 to Oct. 22, 2007) and all EBM Reviews (Oct. 22, 2007) using exploded terms for erythropoietin, anemia and cancer

From the Department of Medicine (Tonelli, Lloyd, Wiebe, Klarenbach) University of Alberta, Edmonton, Alta.; the Department of Medicine (Hemmelgarn, Manns), University of Calgary, Calgary, Alta.; the Department of Medicine (Reiman), Dalhousie University, Halifax, NS; and the Department of Medicine (Reaume), University of Ottawa, Ottawa, Ont. 
(the search strategy is summarized in Appendix 1, available at www.cmaj.ca/cgi/content/full/cmaj.090470/DC1). We also searched registries of clinical trials, manually searched reference lists of relevant reviews and contacted authors of included studies. The full search strategy is available on request from the authors. ${ }^{6}$

\section{Study selection and validity assessment}

We included parallel-group RCTs if they involved adults (18 years or older) with cancer-related anemia and included 30 participants or more in each treatment group; they compared epoetin (alpha or beta) or darbepoetin with a control (no erythropoiesis-stimulating therapy or placebo); and they reported one or more outcomes (all-cause mortality, cardiac event [myocardial infarction, stroke, heart failure or revascularization], hospital admission, quality of life, hypertension, red blood cell transfusions and adverse events). We excluded studies published in a language other than English, French, Spanish or Mandarin.

Two reviewers screened each citation. Trials that were considered to be relevant by any reviewer were retrieved, and the full text was independently assessed by 2 reviewers for inclusion. Disagreements were resolved by a third party through consensus.

We assessed the quality of the studies using characteristics from the Chalmers index ${ }^{9}$ as well as other characteristics that may affect the risk of bias. ${ }^{10-12}$

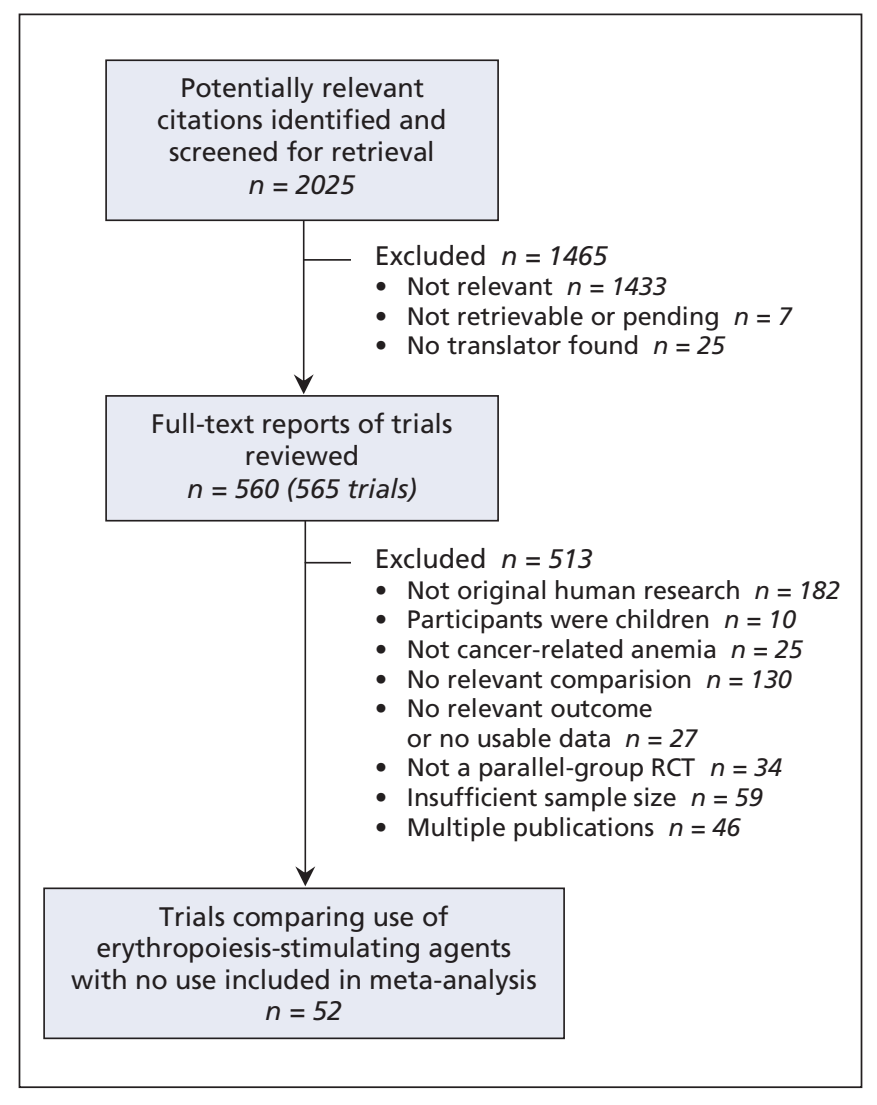

Figure 1: Selection of studies for inclusion in the meta-analysis. $\mathrm{RCT}=$ randomized controlled trial.

\section{Data extraction}

One reviewer extracted data from the selected trials. A second reviewer checked for accuracy. We preferentially captured intention-to-treat analyses where presented.

We classified adverse events as serious if defined as such by the primary authors or if their severity was unspecified but they led to withdrawal from therapy. Because various qualityof-life measures were reported across studies, we considered only measures that were used in more than one study in each comparison.

\section{Data synthesis and analysis}

We pooled results using random-effects models. ${ }^{13}$ Because there was no evidence of clinically relevant differences between epoetin and darbepoetin, ${ }^{6}$ we refer to these agents collectively as erythropoiesis-stimulating agents. We used the relative risk (RR) and the weighted mean difference to summarize dichotomous and continuous results respectively. We quantified statistical heterogeneity using the $I^{2}$ statistic, ${ }^{14,15}$ and we used meta-regression analysis ${ }^{16}$ to examine whether certain variables influenced the association between therapy and clinical outcome.

In subgroup analyses, we examined the relative risk of clinical outcomes in groups stratified by the baseline hemoglobin level $(<100 \mathrm{~g} / \mathrm{L}, 100-120 \mathrm{~g} / \mathrm{L},>120 \mathrm{~g} / \mathrm{L})$, by whether participants did or did not receive chemotherapy and by the target hemoglobin level. We defined these strata to correspond to the criteria of the American Society of Clinical Oncology ${ }^{72}$ for the use of erythropoiesis-stimulating agents in patients with cancer.

\section{Results}

\section{Literature search}

We identified 52 eligible trials $(n=12006)$ that compared the use of erythropoiesis-stimulating agents with no use (Figure 1) ${ }^{3,17-65}$ Forty-two trials $(n=7356)$ compared the use of epoetin alpha or epoetin beta with no use; 10 trials $(n=4650)$ compared the use of darbepoetin alpha with no use. Four trials included patients who were undergoing surgery, had preoperative anemia and received perioperative therapy with an erythropoiesis-stimulating agent. The median duration of treatment was 12 (range 2-28) weeks. The median duration of follow-up (stated in 22 studies) was 12 (range 1-37) months. Details of the studies are summarized in Appendices 2 and 3 (available at www.cmaj.ca/cgi/content/full/cmaj.090470/DC1).

\section{Characteristics of participants}

Participants with solid tumours were included in 30 trials. Ten trials included only participants with hematologic cancers, and 11 trials included participants with solid tumours and hematologic cancers. One trial did not report the type of cancer among participants, and another included patients with myelodysplastic syndrome. Seven trials reported that no chemotherapy was administered during the study. The median age of study participants was 62 (range 48-71) years. Few trials reported the prevalence of comorbidities among study participants (see Appendices 2 and 3, available at www.cmaj.ca/cgi/content/full/cmaj.090470/DC1). 


\section{Methodologic quality}

The 52 trials were generally of poor to moderate quality (Appendix 4, available at www.cmaj.ca/cgi/content/full/cmaj .090470/DC1). We found no evidence of publication bias in a weighted regression test ${ }^{66}$ in which we used results from analyses comparing all-cause mortality (bias $=0.02, p=0.92$ ).

\section{Outcomes}

\section{All-cause mortality}

Twenty-eight trials of 31 comparisons $(n=6525)$ reported on all-cause mortality (Figure 2). Mortality was significantly higher among participants in the treatment groups than in the control groups (RR 1.15, 95\% confidence interval [CI] 1.03 to $1.29, I^{2}=$
$0 \%$ ); this corresponded to a risk difference of $2 \%$ (risk of death $13 \%$ among participants in the control groups). The estimates of treatment effect on mortality were similar when analyses were stratified by agent (RR for epoetin $1.12,95 \%$ CI 0.97 to 1.29 , $I^{2}=0 \%$; RR for darbepoetin $1.22,95 \%$ CI 1.01 to $1.47, I^{2}=$ $0 \%$ ). They were also similar when analyses were stratified by type of cancer (RR for solid tumour $1.16,95 \%$ CI 0.99 to 1.37 ; $\mathrm{RR}$ for hematologic cancer $1.11,95 \% \mathrm{CI} 0.77$ to 1.61 ), were restricted to trials in which the target hemoglobin concentration was $120 \mathrm{~g} / \mathrm{L}$ or less (RR 1.15, 95\% CI 0.94 to 1.40 ), were restricted to trials with a duration longer than the median of 12 weeks (RR $1.15,95 \%$ CI 0.98 to 1.26 ) and excluded trials that studied the perioperative administration of erythropoiesis-stimulating agents (RR 1.15, 95\% CI 1.02 to 1.28 ).

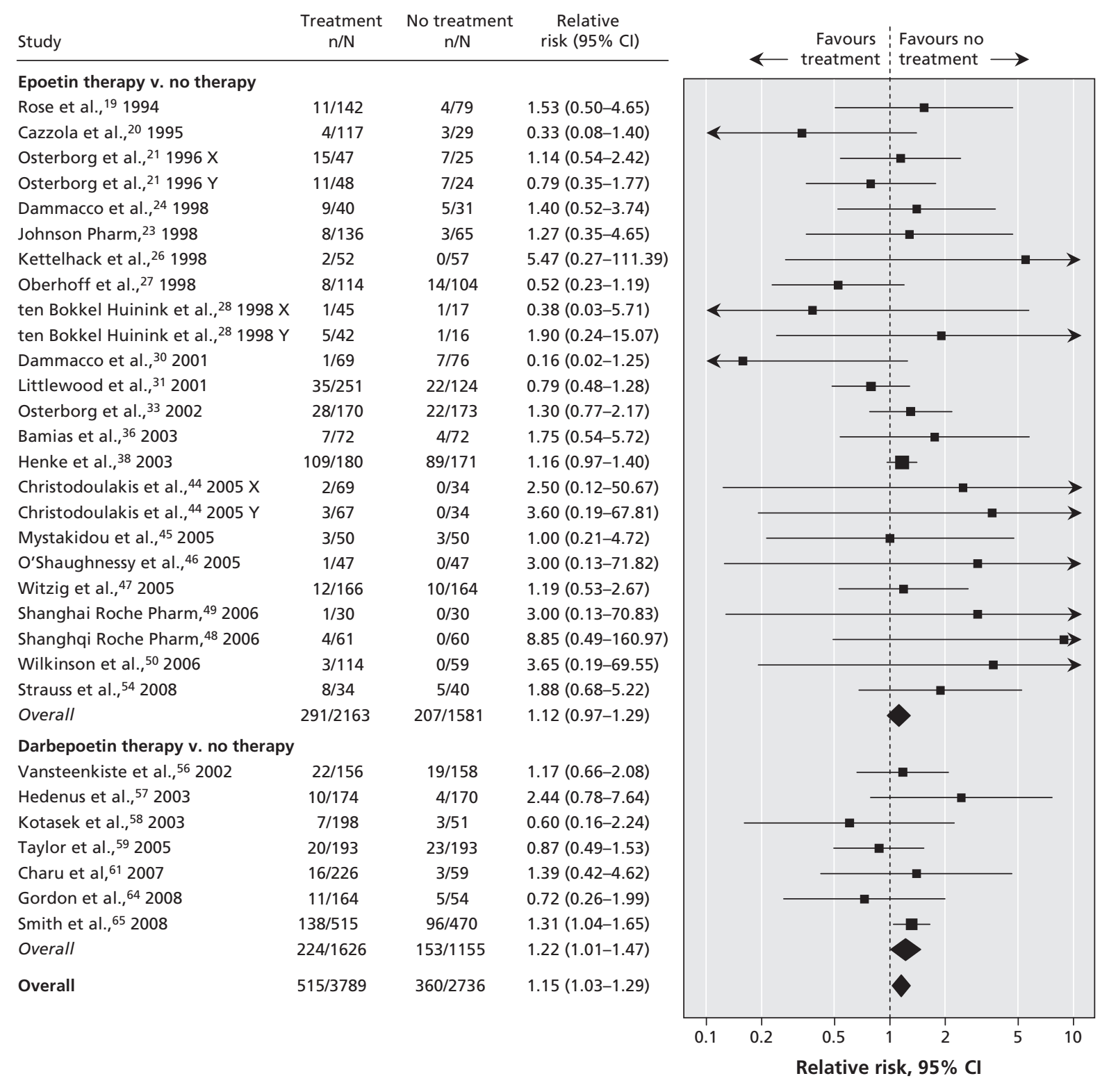

Figure 2: Effect of treatment with erythropoiesis-stimulating agents versus no treatment on all-cause mortality. $\mathrm{Cl}=$ confidence interval. The letters $X$ and $Y$ following study names are indicated for studies with more than one treatment arm. 
None of the variables of interest significantly modified the association between use of erythropoiesis-stimulating agents and mortality in the meta-regression analysis. The potential explanatory variables were duration of treatment, the upper limit of hemoglobin level in the inclusion criteria, the baseline hemoglobin level, use of erythropoiesis-stimulating agents according to the criteria of the American Society of Clinical Oncology, the achieved hemoglobin level, the weekly initial dose of erythropoiesis-stimulating agent, the agent used (epoetin v. darbepoetin), the type of cancer, the use of chemotherapy, the mean age of participants, the percentage of male par- ticipants and the characteristics of study quality (all $p>0.2$ except for study quality, for which $p=0.13$ ).

\section{Cardiovascular events and hypertension}

Fourteen trials ( $n=3281$ ) compared the frequency of cardiovascular events between treatment and control groups; 17 trials $(n=3792)$ compared the frequency of hypertension. The pooled risk of these outcomes did not differ significantly between groups (RR for cardiovascular events $1.12,95 \% \mathrm{CI}$ 0.83 to $1.50, I^{2}=0 \%$; RR for hypertension $1.41,95 \%$ CI 0.94 to $\left.2.12, I^{2}=0 \%\right)$.

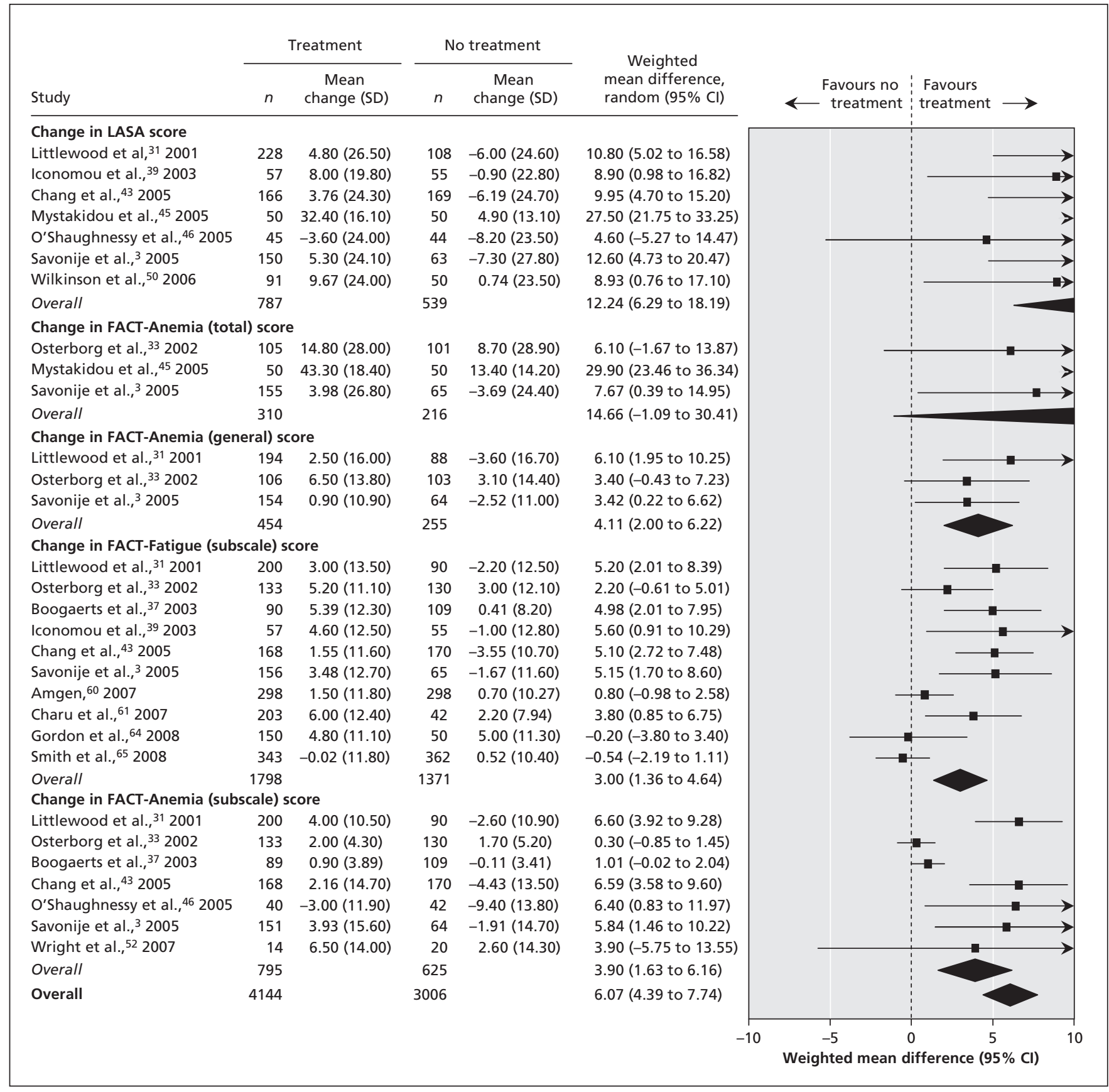

Figure 3: Effect of treatment with erythropoiesis-stimulating agents versus no treatment on change in quality of life. FACT = Functional Assessment of Cancer Therapy, SD = standard deviation, $\mathrm{Cl}=$ confidence interval. 


\section{Health-related quality of life}

One otherwise eligible trial reported changes in generic measures of overall quality of life ${ }^{37}$ however, we excluded it because it was the only study that reported these outcomes.

Seven trials $(n=1326)$ reported changes in disease-specific quality of life using a linear analogue self-assessment (LASA) scale; the changes favoured the use of erythropoiesisstimulating agents (weighted mean difference $12.24,95 \% \mathrm{CI}$ 6.29 to $\left.18.19, I^{2}=81 \%\right)$. Three trials $(n=526)$ using the Total Functional Assessment of Cancer Therapy-Anemia (FACTAnemia) scale also reported changes in quality of life that favoured treatment (weighted mean difference 14.66, 95\% CI -1.09 to 30.41$) ; I^{2}=93 \%$ ]. Three other trials $(n=709)$ using the FACT-General scale reported a change in quality of life that favoured treatment (weighted mean difference 4.11, 95\% CI 2.00 to $\left.6.22, I^{2}=0 \%\right)$. Ten trials $(n=3169)$ reported a sig- nificant change in quality of life among recipients of erythropoiesis-stimulating agents, measured using the Fatigue subscale of the FACT-Anemia scale (weighted mean difference $3.00,95 \%$ CI 1.36 to $4.64, I^{2}=73 \%$ ). For the Anemia subscale of the FACT-Anemia scale, we pooled results from 7 trials $(n=1420)$ and found a significant improvement in quality of life among participants in the treatment groups (weighted mean difference $3.90,95 \%$ CI 1.63 to $6.16, I^{2}=84 \%$ ).

All differences in LASA and FACT scores between treatment and control groups met or exceeded the threshold for minimal clinically important differences (Figure 3). ${ }^{67-71}$ A previous study estimated that a transfusion of 1 unit of red blood cells (increasing the hemoglobin level by $\geq 10 \mathrm{~g} / \mathrm{L}$ ) results in increases in LASA scores (by mean 9.8), FACT-Anemia Fatigue scores (by mean 4.2) and FACT-General scores (by mean 2.5). ${ }^{71}$

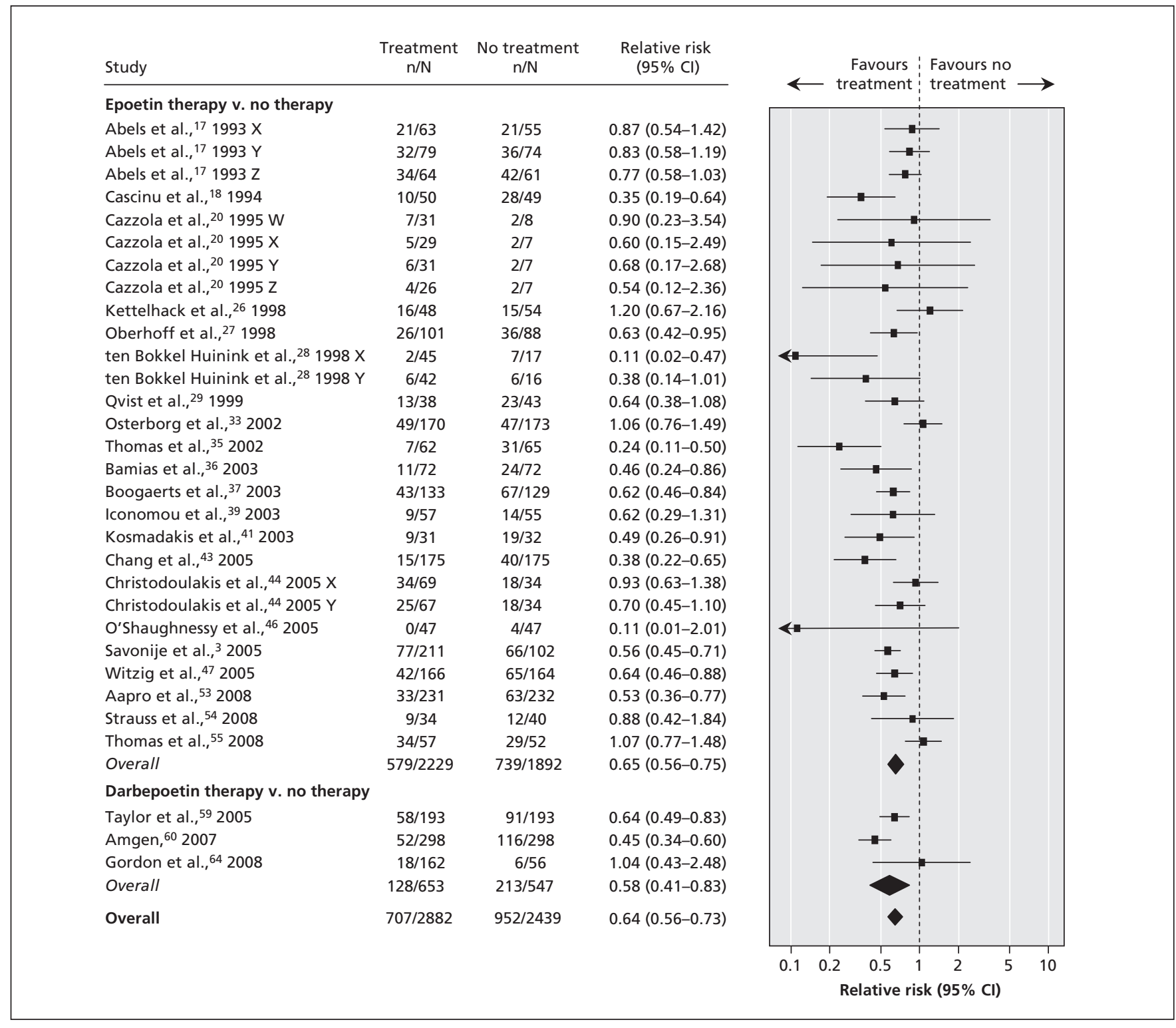

Figure 4: Effect of treatment with erythropoiesis-stimulating agents versus no treatment on blood transfusions. $\mathrm{Cl}=$ confidence interval. The letters $\mathrm{W}, \mathrm{X}, \mathrm{Y}$ and $\mathrm{Z}$ following study names are indicated for studies with more than one treatment arm. 


\section{Blood transfusions}

Twenty-six trials ( $n=5321)$ compared the proportion of participants who received blood transfusions (Figure 4). The use of erythropoiesis-stimulating agents was associated with a reduction in transfusions ( RR $0.64,95 \%$ CI 0.56 to 0.73 ), which translated to a risk difference of $14 \%$ (39\% in the control groups). Fifteen trials compared transfusion volume between groups. After pooling the results, we found significantly fewer units of blood transfused among participants in the treatment groups than among those in the control groups (weighted mean difference -0.80 units, 95\% CI -0.99 to $-0.61) ; I^{2}=12 \%$ ]. Although there is no accepted criterion, this likely constitutes a clinically relevant difference. In the meta-regression analysis, we found that none of the variables of interest (same as those for mortality, plus the presence or absence of prespecified criteria for transfusion) significantly modified the association between treatment and transfusion.

\section{Tumour response}

Two trials $(n=247)$ reported the numbers of participants who had complete and partial tumour responses. The numbers did not differ significantly between treatment and control groups
(RR for complete response in treatment groups $0.88,95 \% \mathrm{CI}$ 0.69 to $1.12, I^{2}=0 \%$; RR for partial response $0.70,95 \% \mathrm{CI}$ 0.44 to $\left.1.11, I^{2}=0 \%\right)$.

\section{Adverse events}

Twenty-one trials $(n=5891)$ reported the incidence of adverse events considered by the investigators to be serious. The risk of serious adverse events was significantly higher among recipients of erythropoiesis-stimulating agents than among control patients (RR 1.16, 95\% CI 1.08 to $1.25, I^{2}=0 \%$ ) (Figure $5)$; this corresponded to a risk difference of 5\% (30\% among control patients). The results did not change after we excluded the single trial in which adverse events of unspecified severity were considered serious if they led to withdrawal from therapy (RR $1.16,95 \%$ CI 1.08 to $1.24, I^{2}=0 \%$ ). In the meta-regression analysis, we found that none of the variables of interest (same as those for mortality) significantly modified the association between treatment and serious adverse events.

Thirteen trials of 14 comparisons $(n=3420)$ reported the frequency of thrombotic events. The risk was significantly higher among patients in the treatment groups than among those in the control groups (RR $1.69,95 \%$ CI 1.27 to $2.24, I^{2}=0 \%$ ).

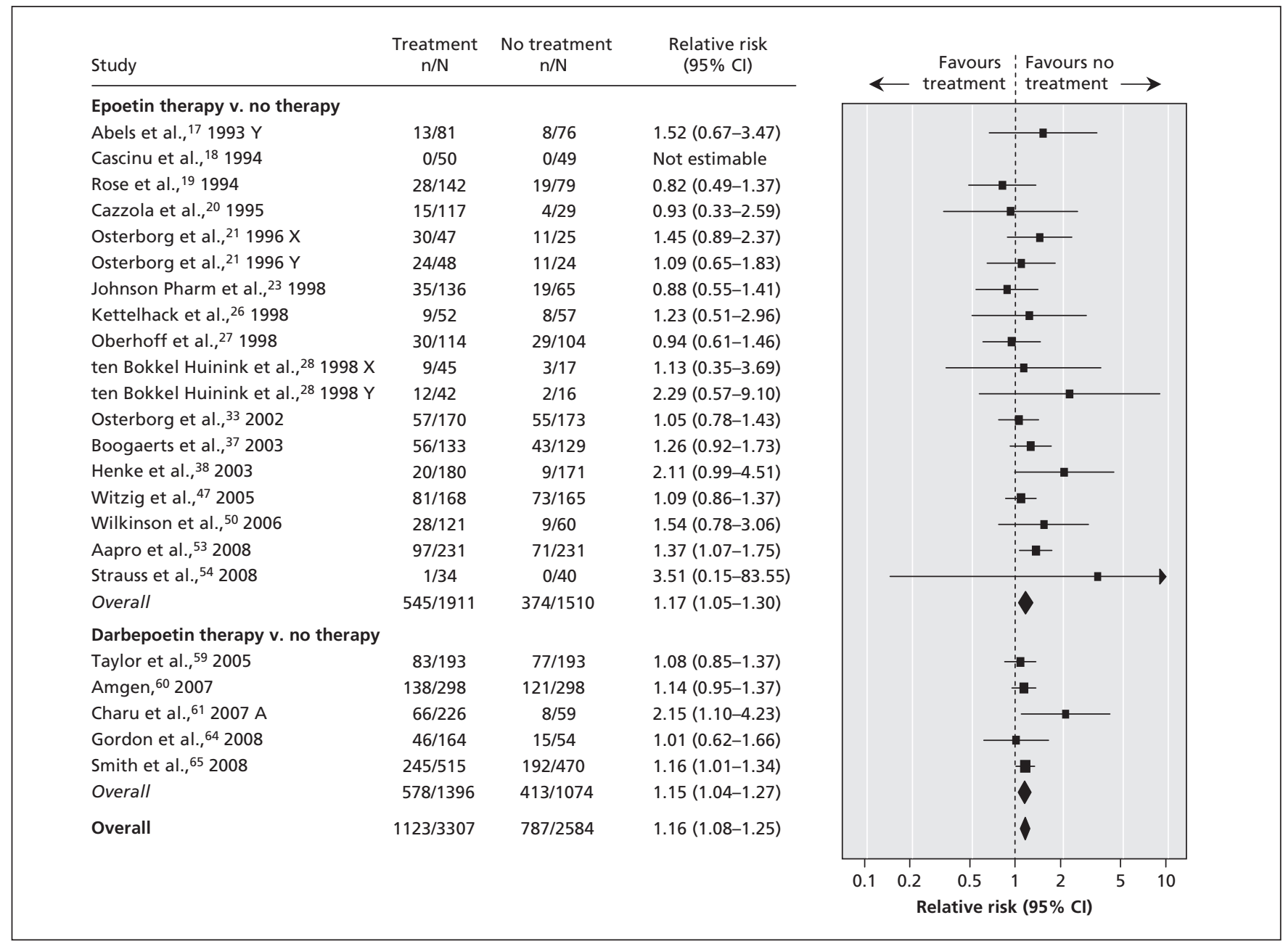

Figure 5: Effect of treatment with erythropoiesis-stimulating agents versus no treatment on serious adverse events. $\mathrm{Cl}=$ confidence interval. The letters $X$ and $Y$ following study names are indicated for studies with more than one treatment arm. 


\section{Subgroup analyses}

The quantity of evidence available for analysis declined substantially as the criteria used to define each subgroup became more specific. For example, only 2 studies ( 3 cohorts) that reported mortality used erythropoiesis-stimulating agents in a fashion that appeared to correspond to all of the criteria of the American Society of Clinical Oncology.

We found little evidence that the clinical benefits or safety of erythropoiesis-stimulating agents in patients defined by the society's criteria differed from the benefits or safety in the total population of patients with cancer treated with erythropoiesisstimulating agents. Specifically, results of the meta-regression analyses comparing the effect of treatment on mortality, serious adverse events, use of blood transfusions and quality of life in subgroups stratified or not stratified according the society's criteria were all nonsignificant $(p \geq 0.25)$. The significant increase in serious adverse events and the significant benefits in terms of transfusion prevention and quality of life were observed both in the subgroup stratified according to the society's criteria and in the nonstratified subgroup (Table 1 and Table 2).

\section{Interpretation}

We found that the use of erythropoiesis-stimulating agents in patients with cancer with anemia resulted in improved scores for several disease-specific measures of quality of life and decreased the use of blood transfusions. The magnitude of im- provement in quality of life appeared clinically relevant and was relatively consistent across trials and instruments. However, the use of erythropoiesis-stimulating agents led to an increased risk of all-cause mortality and a significant increase in the risk of serious adverse events. There was no evidence that treatment influenced the risk of cardiovascular events, admission to hospital or tumour response, although there was a borderline increase in the risk of hypertension associated with treatment.

The clinical relevance of the increases in the risk of death and serious adverse events must be considered in the context of the populations studied. Although the relative magnitude of increased risk was modest (15\%-16\%), the absolute increases in risk were substantial, which reflected the generally adverse underlying prognosis of people with cancer. It is possible, although speculative, that certain patients might choose a reduction in life expectancy in exchange for improved quality of life. However, all of the studies we included were of relatively short duration (median follow-up 12 weeks) and patients were generally aware of the treatment group to which they had been randomly assigned, which may have biased results in favour of treatment with erythropoiesis-stimulating agents. ${ }^{68}$ Future studies that address these knowledge gaps are required to determine whether the apparently increased risk of death associated with the use of erythropoiesis-stimulating agents might be offset by improved quality of life.

Current practices for the use of erythropoiesis-stimulating agents in people with cancer-related anemia are more restrictive

Table 1: Effect of therapy with erythropoiesis-stimulating agents on all-cause mortality, use of blood transfusions and incidence of serious adverse events in patients with anemia related to cancer, by baseline hemoglobin level

\begin{tabular}{|c|c|c|c|c|c|c|c|c|c|}
\hline Patient subgroup & \multicolumn{3}{|c|}{ Mortality } & \multicolumn{3}{|c|}{ Blood transfusions } & \multicolumn{3}{|c|}{ Serious adverse events } \\
\hline \multicolumn{10}{|l|}{$\begin{array}{l}\text { Any hemoglobin level } \\
\text { at baseline }\end{array}$} \\
\hline All patients & $31 / 6525$ & $1.15(1.03-1.29)$ & 0 & $31 / 5321$ & $0.64(0.56-0.73)$ & 55 & $23 / 5891$ & $1.16(1.08-1.25)$ & 0 \\
\hline $\begin{array}{l}\text { No chemotherapy- } \\
\text { induced anemia }\end{array}$ & $8 / 2252$ & $1.22(1.06-1.40)$ & 0 & $7 / 786$ & $0.80(0.66-0.98)$ & 5 & $5 / 1948$ & $1.30(1.00-1.68)$ & 32 \\
\hline $\begin{array}{l}\text { Target hemoglobin } \\
<120 \mathrm{~g} / \mathrm{L}\end{array}$ & $9 / 2436$ & $1.15(0.94-1.40)$ & 2 & $5 / 1315$ & $0.55(0.42-0.73)$ & 47 & $9 / 2560$ & $1.18(1.07-1.31)$ & 0 \\
\hline \multicolumn{10}{|l|}{$\begin{array}{l}\text { Baseline hemoglobin } \\
<100 \mathrm{~g} / \mathrm{L}\end{array}$} \\
\hline $\begin{array}{l}\text { Chemotherapy-induced } \\
\text { anemia, target } \\
\text { hemoglobin }<120 \mathrm{~g} / \mathrm{L}\end{array}$ & $3 / 289$ & $0.77(0.36-1.66)$ & 41 & $2 / 361$ & $0.50(0.29-0.87)$ & 65 & $4 / 505$ & $1.27(1.00-1.60)$ & 0 \\
\hline $\begin{array}{l}\text { Baseline hemoglobin } \\
100-120 \mathrm{~g} / \mathrm{L}\end{array}$ & $14 / 2478$ & $1.16(0.99-1.36)$ & 0 & $12 / 3272$ & $0.57(0.47-0.69)$ & 56 & $11 / 2782$ & $1.22(1.09-1.37)$ & 0 \\
\hline $\begin{array}{l}\text { Baseline hemoglobin } \\
>120 \mathrm{~g} / \mathrm{L}\end{array}$ & $1 / 94$ & $3.00(0.13-71.82)$ & NA & $2 / 175$ & $0.46(0.11-1.88)$ & 34 & $\begin{array}{l}\text { No } \\
\text { studies }\end{array}$ & - & - \\
\hline $\begin{array}{l}\text { Baseline hemoglobin } \\
\text { unclear }\end{array}$ & $2 / 322$ & $2.20(0.38-12.79)$ & 34 & $1 / 109$ & $1.07(0.78-1.48)$ & NA & $1 / 201$ & $0.88(0.55-1.41)$ & NA \\
\hline
\end{tabular}

Note: $\mathrm{RR}=$ relative risk, $\mathrm{Cl}=$ confidence interval, $\mathrm{NA}=$ not applicable. 
Table 2: Effect of therapy with erythropoiesis-stimulating agents on health-related quality of life in patients with anemia related to cancer, by baseline hemoglobin level

\begin{tabular}{|c|c|c|c|c|c|c|c|c|c|}
\hline Patient subgroup & \multicolumn{9}{|c|}{ Measure of quality of life } \\
\hline \multicolumn{10}{|l|}{$\begin{array}{l}\text { Any hemoglobin level } \\
\text { at baseline }\end{array}$} \\
\hline $\begin{array}{l}\text { Chemotherapy-induced } \\
\text { anemia }\end{array}$ & $6 / 1226$ & 9.80 (6.95 to 12.64$)$ & 0 & $7 / 2019$ & 3.87 (2.16 to 5.57$)$ & 60 & $7 / 1420$ & 3.90 (1.63 to 6.16$)$ & 84 \\
\hline $\begin{array}{l}\text { Target hemoglobin } \\
<120 \mathrm{~g} / \mathrm{L}\end{array}$ & $3 / 576$ & 15.59 (3.26 to 27.92$)$ & 91 & $5 / 1687$ & $2.61(-0.12$ to 5.34$)$ & 82 & $2 / 536$ & $3.61(-1.84$ to 9.07$)$ & 92 \\
\hline $\begin{array}{l}\text { Chemotherapy-induced } \\
\text { anemia, target } \\
\text { hemoglobin }<120 \mathrm{~g} / \mathrm{L}\end{array}$ & $\begin{array}{c}\text { No } \\
\text { studies }\end{array}$ & - & - & $1 / 199$ & 4.98 (2.01 to 4.65$)$ & NA & $1 / 198$ & $1.01(-0.02$ to 2.04$)$ & NA \\
\hline $\begin{array}{l}\text { Baseline hemoglobin } \\
100-120 \mathrm{~g} / \mathrm{L}\end{array}$ & $5 / 901$ & 13.77 (5.95 to 21.59$)$ & 85 & $6 / 1712$ & 3.21 (1.16 to 5.26$)$ & 66 & $3 / 587$ & 6.20 (3.80 to 8.60$)$ & 0 \\
\hline $\begin{array}{l}\text { Baseline hemoglobin } \\
>120 \mathrm{~g} / \mathrm{L}\end{array}$ & $1 / 89$ & $4.60(-5.27$ to 14.47$)$ & NA & $\begin{array}{l}\text { No } \\
\text { studies }\end{array}$ & - & - & $1 / 82$ & 6.40 (0.83 to 11.97$)$ & NA \\
\hline $\begin{array}{l}\text { Baseline hemoglobin } \\
\text { unclear }\end{array}$ & $\begin{array}{l}\text { No } \\
\text { studies }\end{array}$ & - & - & $\begin{array}{l}\text { No } \\
\text { studies }\end{array}$ & - & - & $\begin{array}{l}\text { No } \\
\text { studies }\end{array}$ & - & - \\
\hline
\end{tabular}

Note: $\mathrm{Cl}=$ confidence interval, FACT $=$ Functional Assessment of Cancer Therapy, LASA = linear analogue self-assessment, NA $=$ not applicable, RR $=$ relative risk.

than they once were. Guidelines from the American Society of Clinical Oncology ${ }^{72}$ indicate that the agents should not be used unless patients are receiving concurrent chemotherapy; however, they cautiously recommend their use when the hemoglobin level is less than or approaching $100 \mathrm{~g} / \mathrm{L}$ (or 100-120 g/L in certain circumstances, including decreased cardiopulmonary reserve). The recently revised Health Canada label for darbepoetin is similar to the society's criteria: it indicates that the agent should be used for cancer-related anemia under very specific conditions: the presence of nonmyeloid cancer; anemia due to chemotherapy; a hemoglobin level less than $100 \mathrm{~g} / \mathrm{L}$; and a target hemoglobin level of no more than $120 \mathrm{~g} / \mathrm{L}$. Although we identified 2 studies that reported mortality and met the last 3 conditions (and were therefore consistent with the American Society of Clinical Oncology's criteria), both enrolled patients with a form of myeloid cancer (multiple myeloma). Therefore, none of the studies that reported mortality used erythropoiesisstimulating agents in a manner consistent with the current Health Canada label for darbepoetin. The Health Canada label for epoetin is similar to the label for darbepoetin; however, it is slightly less restrictive because it does not specify the hemoglobin level at which therapy should be initiated.

There is a striking lack of data to support Health Canada's labels and the American Society of Clinical Oncology's guide- lines for the use of erythropoiesis-stimulating agents in people with cancer-related anemia. Although it is rational to restrict the use of a potentially harmful therapy, it is unclear whether following the directions in the current label permits the identification of patients with more favourable risk-benefit ratios. In particular, the fact that the risk of death was not significantly increased in the subgroup of trials in which participants met the American Society of Clinical Oncology's criteria does not allay the safety concerns raised by the primary analysis. ${ }^{73,74}$ We found no evidence that the risks or benefits of treatment differed between patients who did or did not receive chemotherapy, or who did or did not meet the society's criteria. This suggests that the most reliable estimates of benefit and harm in these subgroups are likely to be the pooled estimates obtained by combining results from all available trials. ${ }^{73,75}$ These findings suggest that erythropoiesis-stimulating agents should not be routinely used as an alternative to blood transfusion in patients with chemotherapy-induced anemia unless future studies document safety and clinical benefits in this population.

\section{Strengths and limitations}

Our study was an up-to-date, comprehensive systematic review of the clinical implications of use of erythropoiesisstimulating agents for cancer-related anemia. We specifically 
addressed the potential clinical benefits of these agents when used according to current clinical practice guidelines. The studies we included were conducted on several continents over the last decade; enrolled more than 12000 participants in total; involved 3 types of agents (epoetin alpha, epoetin beta and darbepoetin alpha); and focused on people with different types of cancer. Participants in randomized controlled trials tend to be less likely to experience adverse events and more likely to benefit from experimental therapies than unselected individuals with the same diseases. Despite this, the results of our review are likely to be externally valid.

Our study had limitations. Although we reduced the potential for bias by following recommendations for systematic reviews, the methodologic quality of the studies we included was poor to moderate. Also, many of the studies did not specify criteria for administering blood transfusions, which may have reduced internal validity. Second, we excluded studies with fewer than 30 participants; however, this unlikely influenced our conclusions, because the number of participants in the included trials was large. Third, the clinical effects of erythropoiesis-stimulating agents appeared to be homogeneous in the meta-regression analysis; however, this technique has limitations, including low statistical power and the ecological fallacy. ${ }^{76}$ Therefore, the risk-benefit ratio of erythropoiesis-stimulating agents in cancer-related anemia may vary in certain clinical populations.

\section{Conclusion}

Use of erythropoiesis-stimulating agents in patients with cancer-related anemia improved disease-specific measures of quality of life and decreased the use of blood transfusions. However, use of the agents led to an increased risk of all-cause mortality and serious adverse events. We found no evidence that the risks or benefits of treatment differed among patients who did or did not meet recently revised criteria for the use of these agents in patients with cancer. Our findings suggest that existing practice guidelines should be revised to recommend against the routine use of erythropoiesis-stimulating agents as an alternative to blood transfusion in patients with anemia related to cancer.

\section{This article was peer reviewed and fast-tracked.}

Competing interests: Marcello Tonelli, Brenda Hemmelgarn, Braden Manns and Scott Klarenbach received an unrestricted grant awarded to the Alberta Kidney Disease Network from Amgen Inc.; Amgen Inc. did not receive the results before publication and did not dictate the content or focus of the work. Tony Reiman has been an investigator on a number of clinical trials of erythropoiesis-stimiulating agents in cancer patients. No competing interests were declared by the other authors.

Contributors: All of the authors contributed to the conception and design of the study. Marcello Tonelli, Brenda Hemmelgarn, Braden Manns, Anita Lloyd, Natasha Wiebe and Scott Klarenbach contributed to the acquisition of data. Marcello Tonelli, Anita Lloyd and Scott Klarenbach drafted the report. All of the authors contributed to the analysis and interpretation of the data, critically revised the article for important intellectual content and approved the final version submitted for publication.

Acknowledgements: Drs. Tonelli, Hemmelgarn and Manns were supported by New Investigator awards from the Canadian Institutes of Health Research. Drs. Tonelli, Klarenbach and Hemmelgarn were supported by Population Health Investigator awards from the Alberta Heritage Foundation for Medical Research. Dr. Klarenbach was supported by a Scholarship Award from the Kidney Foundation of Canada. Drs. Tonelli, Klarenbach, Hemmelgarn and Manns were supported by an alternative funding plan from the Government of Alberta, the University of Alberta and the University of Calgary.

Additional analyses of between-group risk differences and additional analyses that were not reported in the Canadian Agency for Drugs and Technology in Health (CADTH) review ${ }^{6}$ were undertaken for this article.

Funding: This study was funded by the Canadian Agency for Drugs and Technology in Health.

\section{REFERENCES}

1. Cella D, Kallich J, McDermott A, et al. The longitudinal relationship of hemoglobin, fatigue and quality of life in anemic cancer patients: results from five randomized clinical trials. Ann Oncol 2004; 15:979-86.

2. Caro JJ, Salas M, Ward A, et al. Anemia as an independent prognostic factor for survival in patients with cancer: a systemic, quantitative review. Cancer 2001:91:2214-21.

3. Savonije JH, van Groeningen CJ, van Bochove A, et al. Effects of early intervention with epoetin alfa on transfusion requirement, hemoglobin level and survival during platinum-based chemotherapy: results of a multicenter randomised controlled trial. Eur J Cancer 2005;41:1560-9.

4. Singh AK, Szczech L, Tang KL, et al. Correction of anemia with epoetin alfa in chronic kidney disease. N Engl J Med 2006;355:2085-98.

5. Drueke TB, Locatelli F, Clyne N, et al. Normalization of hemoglobin level in patients with chronic kidney disease and anemia. N Engl J Med 2006;355:2071-84.

6. Tonelli M, Lloyd A, Lee H, et al. Erythropoiesis-stimulating agents for anemia of cancer or of chemotherapy: systematic review and economic evaluation [Technology report no. 119]. Ottawa (ON): Canadian Agency for Drugs and Technologies in Health; 2009. Available: www.cadth.ca/index.php/en/publication/895 (accessed 2009 May 4).

7. Moher D, Cook DJ, Eastwood S, et al. Improving the quality of reports of metaanalyses of randomised controlled trials: the QUOROM statement. Lancet 1999;354:1896-900.

8. Guidelines for authors of CCOHTA Health Technology Assessments reports. Ottawa $(\mathrm{ON})$ : Canadian Coordinating Office for Health Technology Assessments; 2003.

9. Juni P, Altman DG, Egger M. Assessing the quality of randomised controlled trials. In: Egger M, Davey Smith G, Altman DG, editors. Systematic reviews in health care. London (UK): BMJ Books; 2001. p. 87-108.

10. Schulz KF, Chalmers I, Hayes RJ, et al. Empirical evidence of bias. JAMA 1995;273:408-12.

11. Jadad AR, Moore RA, Carrol D, et al. Assessing the quality of reports of randomized clinical trials: Is blinding necessary? Control Clin Trials 1996;17:1-12.

12. Cho MK, Bero LA. The quality of drug studies published in symposium proceedings. Ann Intern Med 1996;124:485-9.

13. DerSimonian R, Laird N. Meta-analysis in clinical trials. Control Clin Trials 1986; 7:177-88.

14. Higgins JPT, Thompson SG. Quanitifying heterogeneity in a meta-analysis. Stat Med 2002;21:1539-58.

15. Higgins JP, Thompson SG, Deeks JJ, et al. Measuring inconsistency in metaanalyses. BMJ 2003;327:557-60.

16. Thompson SG, Higgins JP. How should meta-regression analyses be undertaken and interpreted? Stat Med 2002;21:1559-73.

17. Abels R. Erythropoietin for anaemia in cancer patients. Eur J Cancer 1993;29A (Suppl 2):S2-8.

18. Cascinu S, Fedeli A, Del Ferro E, et al. Recombinant human erythropoietin treatment in cisplatin-associated anemia: a randomized, double-blind trial with placebo. J Clin Oncol 1994;12:1058-62.

19. Rose E, Rai K, Revicki D, et al. Clinical and health status assessments in anemic chronic lymphocytic leukemia (CLL) patients treated with epoetin alfa (EPO) [abstract]. Blood 1994;84(Suppl 10):526a.

20. Cazzola M, Messinger D, Battistel V, et al. Recombinant human erythropoietin in the anemia associated with multiple myeloma or non-Hodgkin's lymphoma: dose finding and identification of predictors of response. Blood 1995;86:4446-53.

21. Osterborg A, Boogaerts MA, Cimino R, et al. Recombinant human erythropoietin in transfusion-dependent anemic patients with multiple myeloma and nonHodgkin's lymphoma - a randomized multicenter study. The European Study Group of Erythropoietin (Epoetin Beta) Treatment in Multiple Myeloma and NonHodgkin's Lymphoma. Blood 1996;87:2675-82.

22. Park HS, Hong DS, Lee SJ, et al. Clinical evaluation of recombinant human erythropoietin (Eprex r) in anemic cancer patients receiving chemotherapy [abstract]. Ann Oncol 1996;7.

23. A placebo-controlled study on the effect of epoetin alfa in patients with malignancy receiving chemotherapy. Raritan (NJ): Johnson \& Johnson Pharmaceutical Research and Development; 2005. Available: http://clinicaltrials.gov/ct2/show /NCT00270166 (accessed 2009 Apr. 27).

24. Dammacco F, Silvestris F, Castoldi GL, et al. The effectiveness and tolerability of epoetin alfa in patients with multiple myeloma refractory to chemotherapy. Int $J$ Clin Lab Res 1998;28:127-34

25. A randomized double-blind placebo-controlled study with subcutaneous recombinant human erythropoietin in patients with low-risk myelodysplastic syndromes. Italian Cooperative Study Group for rHuEpo in Myelodysplastic Syndromes. $\mathrm{Br} \mathrm{J}$ Haematol 1998;103:1070-4 
26. Kettelhack C, Hones C, Messinger D, et al. Randomized multicentre trial of the influence of recombinant human erythropoietin on intraoperative and postoperative transfusion need in anaemic patients undergoing right hemicolectomy for carcinoma. Br J Surg 1998;85:63-7.

27. Oberhoff C, Neri B, Amadori D, et al. Recombinant human erythropoietin in the treatment of chemotherapy-induced anemia and prevention of transfusion requirement associated with solid tumors: a randomized, controlled study. Ann Oncol 1998;9:255-60

28. ten Bokkel Huinink WW, de Swart CA, van Toorn DW, et al. Controlled multicentre study of the influence of subcutaneous recombinant human erythropoietin on anaemia and transfusion dependency in patients with ovarian carcinoma treated with platinum-based chemotherapy. Med Oncol 1998;15:174-82.

29. Qvist N, Boesby S, Wolff B, et al. Recombinant human erythropoietin and hemoglobin concentration at operation and during the postoperative period: reduced need for blood transfusions in patients undergoing colorectal surgery-prospective double-blind placebo-controlled study. World J Surg 1999;23:30-5.

30. Dammacco F, Castoldi G, Rodjer S. Efficacy of epoetin alfa in the treatment of anaemia of multiple myeloma. Br J Haematol 2001;113:172-9.

31. Littlewood TJ, Bajetta E, Nortier JW, et al. Effects of epoetin alfa on hematologic parameters and quality of life in cancer patients receiving nonplatinum chemotherapy: results of a randomized, double-blind, placebo-controlled trial. J Clin Onco 2001;19:2865-74.

32. Huddart RA, Welch RS, Chan S, et al. A prospective randomised comparativegroup evaluation of epoetin alfa for the treatment of anaemia in UK cancer patients receiving platinum-based chemotherapy. Ann Oncol 2002;13(Suppl 5):177.

33. Osterborg A, Brandberg Y, Molostova V, et al. Randomized, double-blind, placebo-controlled trial of recombinant human erythropoietin, epoetin beta, in hematologic malignancies. J Clin Oncol 2002;20:2486-94.

34. Pronzato P, Cortesi E, van der Rijt C, et al. Early intervention with epoetin alfa in breast cancer patients undergoing chemotherapy: results of a randomized, multicenter, phase IIIb study (EPO-INT-47 Study Group). Ann Oncol 2002;13:168.

35. Thomas H, McAdam KF, Thomas RJ, et al. Early intervention with epoetin alfa for treatment of anaemia and improvement of quality of life in cancer patients undergoing myelotoxic chemotherapy. Ann Oncol 2002;13(Suppl 5):177.

36. Bamias A, Aravantinos G, Kalofonos C, et al. Prevention of anemia in patient with solid tumors receiving platinum-based chemotherapy by recombinant human erythropoietin ( $\mathrm{rHuEpo}$ ): a prospective, open label, randomized trial by the Hellenic Cooperative Oncology Group. Oncology 2003;64:102-10.

37. Boogaerts M, Coiffier B, Kainz C, et al. Impact of epoetin beta on quality of life in patients with malignant disease. Br J Cancer 2003;88:988-95.

38. Henke M, Laszig R, Rube C, et al. Erythropoietin to treat head and neck cancer patients with anaemia undergoing radiotherapy: randomised, double-blind, placebocontrolled trial. Lancet 2003;362:1255-60.

39. Iconomou G, Koutras A, Rigopoulos A, et al. Effect of recombinant human erythropoietin on quality of life in cancer patients receiving chemotherapy: results of a randomized, controlled trial. J Pain Symptom Manage 2003;25:512-8.

40. Janinis J, Dafni U, Aravantinos G, et al. Quality of life (QoL) outcome of epoietinalfa (EPO-A) in anemic cancer patients undergoing platinum or non-platinumbased chemotherapy: a randomized study conducted by the Hellenic Cooperative Oncology Group [abstract 3172]. Proc Am Soc Clin Oncol 2003;22:789.

41. Kosmadakis N, Messaris E, Maris A, et al. Perioperative erythropoietin administration in patients with gastrointestinal tract cancer: prospective randomized doubleblind study. Ann Surg 2003;237:417-21

42. Recasens V, Rubio-Martinez A, Gomez-Barrera M, et al. A pharmacoeconomic analysis comparing epoetin alpha vs. transfusion in patients with anemia associated with multiple myeloma [abstract 1801]. Blood 2003;102(11).

43. Chang J, Couture F, Young S, et al. Weekly epoetin alfa maintains hemoglobin, improves quality of life, and reduces transfusion in breast cancer patients receiving chemotherapy. J Clin Oncol 2005;23:2597-605.

44. Christodoulakis M, Tsiftsis DD, Hellenic Surgical Oncology Perioperative EPOSG. Preoperative epoetin alfa in colorectal surgery: a randomized, controlled study. Ann Surg Oncol 2005;12:718-25.

45. Mystakidou K, Kalaidopoulou O, Katsouda E, et al. Evaluation of epoetin supplemented with oral iron in patients with solid malignancies and chronic anemia not receiving anticancer treatment. Anticancer Res 2005;25:3495-500.

46. O'Shaughnessy JA, Vukelja SJ, Holmes FA, et al. Feasibility of quantifying the ef fects of epoetin alfa therapy on cognitive function in women with breast cancer undergoing adjuvant or neoadjuvant chemotherapy. Clin Breast Cancer 2005;5:439-46.

47. Witzig TE, Silberstein PT, Loprinzi CL, et al. Phase III, randomized, double-blind study of epoetin alfa compared with placebo in anemic patients receiving chemotherapy. J Clin Oncol 2005;23:2606-17.

48. Multicenter, open label study of NeoRecormon prevention and treatment for anemia in adult patients with solid tumors and treated with platinum-based chemotherap prone to induce anemia. Shanghai (China): Shanghai Roche Pharmaceuticals; 2006.

49. Multicenter, open label study of NeoRecormon treatment for anemia in adult patient with multiple myeloma, low grade non-Hodgkin's lymphoma or chronic lymphocytic leukemia who have a relatively erythropoietin deficiency and are receiving antitumor chemotherapy. Shanghai (China): Shanghai Roche Pharmaceuticals; 2006.

50. Wilkinson PM, Antonopoulos M, Lahousen M, et al. Epoetin alfa in platinumtreated ovarian cancer patients: results of a multinational, multicentre, randomised trial. Br J Cancer 2006;94:947-54.

51. Machtay M, Pajak TF, Suntharalingam M, et al. Radiotherapy with or without erythropoietin for anemic patients with head and neck cancer: a randomized trial of the Radiation Therapy Oncology Group (RTOG 99-03). Int J Radiat Oncol Biol Phys 2007;69:1008-17.
52. Wright JR, Ung YC, Julian JA, et al. Randomized, double-blind, placebocontrolled trial of erythropoietin in non-small-cell lung cancer with disease-related anemia. J Clin Oncol 2007;25:1027-32.

53. Aapro M, Leonard RC, Barnadas A, et al. Effect of once-weekly epoetin beta on survival in patients with metastatic breast cancer receiving anthracycline- and/or taxane-based chemotherapy: results of the Breast Cancer-Anemia and the Value of Erythropoietin (BRAVE) study. J Clin Oncol 2008;26:592-8.

54. Strauss HG, Haensgen G, Dunst J, et al. Effects of anemia correction with epoetin beta in patients receiving radiochemotherapy for advanced cervical cancer. Int $J$ Gynecol Cancer 2008;18:515-24.

55. Thomas G, Ali S, Hoebers FJ, et al. Phase III trial to evaluate the efficacy of maintaining hemoglobin levels above $12.0 \mathrm{~g} / \mathrm{dL}$ with erythropoietin vs above $10.0 \mathrm{~g} / \mathrm{dL}$ without erythropoietin in anemic patients receiving concurrent radiation and cisplatin for cervical cancer. Gynecol Oncol 2008;108:317-25.

56. Vansteenkiste J, Pirker R, Massuti B, et al. Double-blind, placebo-controlled, randomized phase III trial of darbepoetin alfa in lung cancer patients receiving chemotherapy. J Natl Cancer Inst 2002;94:1211-20.

57. Hedenus M, Adriansson M, San Miguel J, et al. Efficacy and safety of darbepoetin alfa in anaemic patients with lymphoproliferative malignancies: a randomized, double-blind, placebo-controlled study. Br J Haematol 2003;122:394-403.

58. Kotasek D, Steger G, Faught W, et al. Darbepoetin alfa administered every 3 weeks alleviates anaemia in patients with solid tumours receiving chemotherapy; results of a double-blind, placebo-controlled, randomised study. Eur J Cancer 2003;39:2026-34.

59. Taylor K, Ganly P, Charu V, et al. Randomized, double-blind, placebo-controlled study of darbepoetin alfa every 3 weeks for the treatment of chemotherapy-induced anemia [abstract]. Blood 2005;106:abstract 3556.

60. Results from a phase 3, randomized, double-blind, placebo-controlled study of darbepoetin alfa in subjects with previously untreated extensive-stage small-cell lung cancer (SCLC) treated with platinum plus etoposide chemotherapy. Thousand Oaks (CA): Amgen; 2007.

61. Charu V, Belani CP, Gill AN, et al. Efficacy and safety of every-2-week darbepoetin alfa in patients with anemia of cancer: a controlled, randomized, open-label phase II trial. Oncologist 2007;12:727-37.

62. Kotasek D, Canon JL, Mateos MV, et al. A randomized, controlled trial comparing darbepoetin alfa correction/maintenance dosing with weekly dosing for treating chemotherapy-induced anemia. Curr Med Res Opin 2007;23:1387-401.

63. Overgaard J, Hoff C, Hansen HS, et al. Randomized study of the importance on Novel Erythropoiesis Stimulating Protein $\left(\right.$ Aransep $\left.^{\circledast}\right)$ for the effect of radiotherapy in patients with primary squamous cell carcinoma of the head and neck (HNSCC) the Danish Head and Neck Cancer Group DAHANCA 10 rand [abstract 6LB]. Eur J Cancer 2007:5:7.

64. Gordon D, Nichols G, Ben-Jacob A, et al. Treating anemia of cancer with every-4week darbepoetin alfa: final efficacy and safety results from a phase II, randomized, double-blind, placebo-controlled study. Oncologist 2008;13:715-24.

65. Smith RE Jr, Aapro MS, Ludwig H, et al. Darbepoetin alpha for the treatment of anemia in patients with active cancer not receiving chemotherapy or radiotherapy: results of a phase III, multicenter, randomized, double-blind, placebo-controlled study. J Clin Oncol 2008;26:1040-50.

66. Egger M, Davey Smith G, Schneider M, et al. Bias in meta-analysis detected by a simple, graphical test. BMJ 1997;315:629-34

67. Cella D, Eton DT, Lai JS, et al. Combining anchor and distribution-based methods to derive minimal clinically important differences on the Functional Assessment of Cancer Therapy (FACT) anemia and fatigue scales. J Pain Symptom Manage 2002;24:547-61.

68. Kallich J, McDermott A, Xu X, et al. The relationship between patient knowledge of hemoglobin levels and health-related quality of life. Qual Life Res 2006;15:57-68.

69. Kimel M, Leidy NK, Mannix S, et al. Does epoetin alfa improve health-related quality of life in chronically ill patients with anemia? Summary of trials of cancer, HIV/AIDS, and chronic kidney disease. Value Health 2008;11:57-75.

70. Leaf DE, Goldfarb DS. Interpretation and review of health-related quality of life data in CKD patients receiving treatment for anemia. Kidney Int 2009; 75:15-24 Epub 2008 Aug. 27.

71. Patrick DL, Gagnon DD, Zagari MJ, et al. Assessing the clinical significance of health-related quality of life (HrQOL) improvements in anaemic cancer patients receiving epoetin alfa. Eur J Cancer 2003;39:335-45.

72. Rizzo JD, Somerfield MR, Hagerty KL, et al. Use of epoetin and darbepoetin in patients with cancer: 2007 American Society of Clinical Oncology/American Society of Hematology clinical practice guideline update. J Clin Oncol 2008;26:132-49.

73. Population by year, by province and territory. Ottawa (ON): Statistics Canada; 2007. Available: www40.statcan.gc.ca/101/cst01/demo02a-eng.htm (updated 2007; accessed 2008 Nov. 19).

74. Deeks JJ, Altman DG, Bradburn MJ. Statistical methods for examining heterogeneity and combining results from several studies in meta-analysis. In: Egger M, Davey Smith G, Altman DG, editors. Systematic reviews in health care: meta-analysis in context. 2nd ed. London (UK): BMJ Publishing Group; 2001. p. 285-312.

75. DeMets DL, Califf RM. Lessons learned from recent cardiovascular clinical trials: Part I. Circulation 2002;106:746-51.

76. Laupacis A, Keown P, Pus N, et al. A study of the quality of life and cost-utility of renal transplantation. Kidney Int 1996;50:235-42.

Correspondence to: Dr. Marcello Tonelli, University of Alberta, 7-129 Clinical Science Building, 8440-112 St., Edmonton AB T6B 2B7; fax 780 407-7878; mtonelli-admin@med.ualberta.ca 